\title{
Investigation of High School Students' Physical Education and Sports Lesson Exam Anxiety
}

\section{Lise Öğrencilerinin Beden Eğitimi ve Spor Dersi Sınav Kaygılarının Incelenmesi}

Ali Erdoğan
Faculty of Sport Sciences, Karamanoğlu Mehmetbey University

Volkan Sural ${ }^{1}$

Ministry of National Education (MoNE), Yenikent ILKSAN Anatolian High School

Received: August 28, 2021

Accepted: September 19, 2021

Online Published: September 21, 2021

DOI: $10.30655 /$ besad.2021.38

https://doi.org/10.30655/besad.2021.38

\section{Öz}

Bu çalışmanın amacl; lise öğrencilerinin beden eğitimi ve spor dersi sınav kaygılarını çeşitli değiş̧kenler açısından değerlendirmektir. Nicel araştırma yaklaşımlarından tarama modeline göre gerçekleştirilen araştırma grubunu 2020-2021 eğitim-öğretim yılında Ankara ili Sincan ilçesi Milli Eğitim Müdürlügüne bağlı liselerde öğrenim gören 454 öğrenci oluşturmaktadır. Çalışmanın verileri Kişsisel Bilgi Formu ve Beden Eğitimi Dersi Sınav Kaygısı Envanteri kullanılarak çevrimiçi ortamda toplanmıştır. Araştırmada veri toplama araçları ile elde edilen bilgilerin analizi için, SPSS 23 for Windows paket programı kullanılarak bilgisayar ortamında gerçekleştirilmiştir. Aykırı uç değer analizinde ise verilerin Z skoru değerleri kontrol edilmiştir. Ayrıca aritmetik ortalama, standart sapma, çarpıklık ve basıklık değerlerini içeren betimsel analizler kontrol edilmiştir. Araştırma sonuçlarına göre, cinsiyetlerine göre beden eğitimi dersi sınav kaygısından almış oldukları puan ortalamaları arasında istatistiksel olarak anlamlı bir fark olduğu görülmüştür. Araştırmaya katılan kız öğrencilerin erkek öğrencilere göre algıladıkları stres düzeyinin daha yüksek olduğu görülmüş̧ür. Spor yapma durumu ve sınıf düzeylerine göre ise beden eğitimi ve spor dersi sınav kaygısı açısından anlamı bir fark bulunamamıştır. Ayrıca beden eğitimi ve spor dersi sınav kaygısı ölçeği alt boyutlarından algılanan kontrol alt boyutu en yüksek değer ile beden eğitimi dersi için kaygının yüksek olduğu sonucuna ortaya çıkmıştır. Fiziksel gerginlik alt boyutu ise en düşük puan aldığı görülmüştür ve katılımcıların fiziksel gerginlik düzeylerinin ortalamanın altında olduğu sonucuna ulaşılmıştır. Konunun daha derinlemesine incelenebilmesi için farklı örneklemler ve modellerde kurgulanmış çalışmaların yapılması önerilebilir.

Anahtar Kelimeler: Beden eğitimi ve spor, fiziksel aktivite, stres, kaygı, sınav kaygısı

\footnotetext{
${ }^{1}$ Corresponding Author: Volkan Sural volkansural75@gmail.com

MoNE Yenikent ILKSAN Anatolian High School, Ankara, Turkey
} 


\section{Abstract}

The aim of this study; The aim of this study is to evaluate the physical education and sports course exam anxiety of high school students in terms of various variables. The research group, which was carried out according to the survey model, which is one of the quantitative research approaches, consists of 454 students studying in high schools affiliated to the Directorate of National Education in the Sincan district of Ankara in the academic year of 2020-2021. The data of the study were collected online using the Personal Information Form and the Physical Education Lesson Exam Anxiety Inventory. For the analysis of the information obtained with the data collection tools in the research, the SPSS 23 for Windows package program was used in the computer environment. In the outlier analysis, the Z-score values of the data were controlled. In addition, descriptive analysis including arithmetic mean, standard deviation, skewness and kurtosis were checked. According to the results of the research, it was observed that there was a statistically significant difference between the mean scores of physical education lesson exam anxiety according to their gender. It has been observed that the female students participating in the research have a higher perceived stress level than male students. No significant difference was found in terms of physical education and sports lesson exam anxiety according to the status of doing sports and grade levels. In addition, it was concluded that the perceived control sub-dimension, which is one of the physical education and sports lesson test anxiety scale sub-dimensions, has the highest value and the anxiety for the physical education lesson is high. It was observed that the physical tension sub-dimension received the lowest score, and it was concluded that the physical tension levels of the participants were below the average. In order to examine the subject in more depth, it may be recommended to conduct studies designed with different samples and models.

Keywords: Physical education and sport, physical activity, stress, worry, exam anxiety

\section{Giriş}

Beden eğitimi genel eğitimin ayrılmaz bir parçası ve tamamlayıcısıdır. Çünkü eğitimin hedefindeki insan fiziksel, zihinsel ve ruhsal bir varlıktır. Bundan dolayı insan bir bütün olarak düşünülüp sadece bilişsel gelişimi değil aynı zamanda duyuşsal ve psikomotor gelişimi de göz önüne alınarak eğitim sürecinin tasarlanması gerekmektedir. Bedensel eğitime zihinsel eğitimle aynı derecede önem verilmelidir.

Eğitimin nihai amacı bireyin hayata hazırlanması ve hayatını sürdürebilecek yetilerle donatılmasıdır. En nihayetinde ise mutlu bir birey olarak yaşamını sürdürmesidir. Beden eğitimi ve spor bu süreçte önemli bir rol oynamaktadır. Beden eğitimi ve spor dersi Türkiye'de eğitimin ilk kademesinden lise eğitiminin sonuna kadar her kademede yer almaktadır. Kademeler ilerledikçe beden eğitimi ve spor dersinin uygulanışı ve amacı değişim göstermektedir. Beden eğitimi ve spor dersi ilkokul kademesinde daha çok oyun etkinlikleri ve oyun yoluyla öğrenme şeklinde yer alırken lise kademesinde hareket yoluyla öğrenme, sağlıklı yaşama ve spor kültürü oluşturma, ilgi, istek ve ihtiyaçlar doğrultusunda mesleğe yönlendirme şeklinde yer almaktadır.

Beden eğitimi ve spor dersi her ne kadar oyun etkinlikleri, fiziksel aktivite ve spor müsabakaları şeklinde uygulansa da bir üst kademeye geçmek ya da mezun olmak için sınavından başarılı olunması gereken bir derstir. Dersten başarılı olma baskısı strese ve sınav kaygısına neden olabilir. Sınav kaygısı hayatın her alanında olduğu gibi beden eğitimi ve spor dersinde de mevcuttur. Beden eğitimi ve spor dersi sınavları hem yazılı hem de uygulamalı olarak yapılabilmektedir. Uygulama kısmının doğru yapılması ve uygulamayı yaparken sınıf arkadaşları tarafından seyredilmesi öğrencinin olumsuz etkilenip strese girmesini ve kaygılanmasını beraberinde getirebilmektedir. Kaygı, bireyin bir uyaran karşısında duygusal, ruhsal ve fizyolojik olarak farklılaşmalarla ortaya çıkan uyarılmışlık hali olarak adlandırıı (Öner ve Le Compte, 1998). Sınav kaygısı ise bir sınavda veya benzer bir değerlendirme durumunda muhtemel başarısızlık veya düşük performans endişeleriyle ilgili bir dizi bilişsel, fizyolojik ve davranışsal tepkileri 
ifade eder (Beidel, 1991). Sınav kaygısı genel kaygıdan farklı olarak, bireyin sonradan kazandığı ve öğrenciliği devam ettiği sürece hissedeceği bir unsurdur. Bireylerin meslek hayatlarını ve dolayısıyla bütün bir yaşamını etkileyecek olan bir sınav ile karşılaşmak bireyleri yüksek kaygıya itebilmektedir (Gökçe, 2015).

Sınav kaygısının düzeyi öğrenme ve başarıyı olumlu ya da olumsuz olarak etkileyebilmektedir. Yüksek sınav kaygısı ile başarı arasında negatif ilişki olduğu sonucuna ulaşan bir çok çalışma mevcuttur (Bay, Tuğluk ve Gençdoğan, 2004; Chapell vd., 2005; Putwain, Woods \& Symes, 2010; Zeidner, 1998). Cüceloğlu'na (2015) göre kaygı ile öğrenme arasındaki ilişki, güdülenme ve başarı arasındaki ilişkiyle benzerdir. Öğrenilen bilgi basit ve kolaysa, yüksek kaygı derecesi bu bilginin çabuk öğrenilmesine yol açar. Öğrenilen bilgi karmaşık ve zorsa, o zaman yüksek kaygı öğrenmeyi zorlaştırır. Beden eğitimi ve spor dersinde öğrenme süreci hem basit hem de karmaşık temalar içerir. Bu nedenle öğrenmenin kalıcı olması ve başarıya ulaşmak için beden eğitimi ve spor dersi sınav kaygısının kontrol edilebilir düzeyde olması gerekir.

Ulusal (Aba; 2018; Dalkıran, 2012; Erten, 2020; Genç, 2013; Kayapınar, 2006; Tekbaş, 2009) ve uluslararası (Mohammadyari, 2012; Putwain, 2007; Travlos, 2010; Yusefzadeh, Iranagh ve Nabilou, 2019) literatürde öğrencilerin öğrenme, akademik başarı ve stres düzeyleri gibi değişkenler ile sınav kaygısı arasındaki ilişkiyi inceleyen birçok çalışmaya rastlanmıştır. Ancak lise öğrencilerinin beden eğitimi ve spor dersi sınav kaygısını inceleyen herhangi bir çalışmaya rastlanmamıştır. Bu konuda yapılacak bir araştırmanın literatüre katkı sağlayacağı düşünülmektedir. Bu doğrultuda bu çalışmanın amacı; lise öğrencilerinin beden eğitimi ve spor dersi sınav kaygılarını çeşitli değişkenler açısından incelemektir.

\section{Yöntem}

Bu araştırmanın amacı lise öğrencilerinin beden eğitimi ve spor dersi sınav kaygı düzeyleri ile cinsiyet, sınıf düzeyi ve spor yapma durumu değişkenleri arasındaki ilişkinin incelenmesidir. Bu amaç doğrultusunda araştırmada kullanılan model ilişkisel tarama modelidir. ilişskisel tarama modeli, en az iki veya daha fazla değişkenin aralarında olan değişim varlığı veya seviyesini tespit etmeyi hedefleyen bir modeldir (Karasar, 2017).

\section{Evren ve Örneklem}

Çalışma evrenini Ankara ili Sincan ilçesi Milli Eğitim Müdürlüğüne bağlı liselerde öğrenim gören 6416 lise öğrencisi oluştururken örneklemini ise çalışmaya katılmayı gönüllülük esasına dayalı olarak kabul eden 454 lise öğrencisi oluşturmaktadır.

Tablo 1. Katıımcıların demografik özellikleri.

\begin{tabular}{llll}
\hline & & $\mathbf{N}$ & $\mathbf{f}$ \\
\hline Cinsiyet & Erkek & 162 & 35.7 \\
& KIZ & 292 & 64.3 \\
& & & 23.8 \\
& 9. sinif & 108 & 27.3 \\
& 10. sinif & 124 & 24.9 \\
& 11.sinif & 113 & 24.0 \\
\hline
\end{tabular}

Örneklem grubunun oluşturulmasında kolayda/uygun örneklem yolu kullanılmış ve veriler çevrimiçi anket formu kullanılarak toplanmıştır. Kolayda örnekleme yöntemi, araştırmanın evreninde olan kişilere 
kolay bir şekilde ulaşılarak verileri toplanmasını ifade etmektedir (Büyüköztürk ve ark., 2018). Araştırmaya katılanların 162 (\%35.7) erkek ve 292 (\%64.3) kız öğrenciler oluşturmaktadır. Ayrıca katıımcıların 108 (\%23.8) dokuzuncu sınıf, 124 (\%27.3) onuncu sınıf, 113 (\%24.9) on birinci sınıf ve 109 (\%24) on ikinci sınıf öğrencisinden oluşmaktadır.

\section{Veri Toplama Araçları}

Envanter Danthony, Mascret ve Cury (2019) tarafından öğrencilerin beden eğitimi dersine yönelik sınav kaygısını belirlemek amacıyla geliştirilmiş Beden Eğitimi Dersi Sınav Kaygısı Envanteri isimli ölçek kullanılmıştır. Ölçeğin Türk kültürüne uyarlamasını Devrilmez, Çiy, Bilgiç ve Dervent (2021) tarafından gerçekleştirilmiştir. Ölçek 19 maddeden oluşmakta ve yargılar 4' lü likert tipine (1=Hiçbir zaman, 4=Her zaman) göre değerlendirilmiştir. Ölçek 5 alt boyuttan oluşmaktadır. Her bir alt boyut için elde edilen cronbach alfa değerleri endişe alt boyutu .68; kendi kendine odaklanma alt boyutu .77; bedensel belirtiler alt boyutu .75; fiziksel gerginlik alt boyutu .86; algılanan kontrol alt boyutu .89 ve ölçeğin genel cronbach alfa katsayısı 81 olarak belirtilmiştir. Ölçeğin doğrulayıcı faktör analizi sonucunda elde edilen $\mathrm{X} 2 / \mathrm{df}=3.06$; RMSEA=.05; GFI=.94; $\mathrm{CFI=.96;NFI=.94;IFI=.93;} \mathrm{AGFI=.93} \mathrm{olarak} \mathrm{belirtilmiştir.} \mathrm{Hu} \mathrm{ve} \mathrm{Bentler} \mathrm{(1999)}$ tarafından öngörüldüğü gibi, 19 maddelik ve beş alt boyutlu ölçek yapısal olarak değerlendirildiğinde kabul edilebilir uyum değerlerine sahip olduğu görülmektedir.

\section{Veri Toplama Süreci}

Verilerin toplanması aşamasına geçmeden önce Karamanoğlu Mehmetbey Üniversitesi Etik Komisyonundan çalışma için gerekli etik kurul raporu alınmıştır (Etik kurul no:03-2021/46). Veriler, 15-22 Mart 2021 tarihleri arasında sosyal medya platformları (WhatsApp vb.) üzerinden paylaşılarak online anket yoluyla toplanmıştır.

\section{Veri Analizi}

Verilerin analizinde SPSS 23 paket programı kullanılmıştır. Verilerin analizine geçilmeden önce missing value incelemesi yapılmış ve missing value tespit edilememiştir. Aykırı uç değer analizinde ise verilerin $Z$ skoru değerleri kontrol edilmiştir. Bu yöntem Z skoru +3 ile -3 değerleri dışında olan değerlerin veri setinden çıkarılmasını kapsar. Yapılan analizde 17 tane veri aykırı uç değer olarak tespit edilmiş ve veri setinden çıkarılmıştır. Ayrıca aritmetik ortalama, standart sapma, çarpıklık ve basıklık değerlerini içeren betimsel analizler kontrol edilmiştir. Katılımcılardan toplanan veriler doğrultusunda Beden Eğitimi ve Spor Dersi sınav kaygısı ölçeği ve katıımcıların kişisel bilgileri arasındaki ilişkiyi tespit etmek için cinsiyet ve spor yapma durumunun incelenmesinde bağımsız örneklemler t testi, sınıf düzeyine göre yapılan incelemede ise tek yönlü varyans analizi (one way ANOVA) testi kullanılmıştır.

\section{Bulgular}

Lise öğrencilerinin beden eğitimi ve spor dersi sınav kaygısı ölçeği alt boyutlarından endişe alt boyutu ortalama puanı $(\bar{x}=2.51)$, kendi kendine odaklanma alt boyutu $(\bar{x}=1.92)$, bedensel belirtiler alt boyutu $(\bar{x}=1.73)$, fiziksel gerginlik alt boyutu ( $\bar{x}=1.45)$, algılanan kontrol alt boyutu için ise $(\bar{x}=2.98)$ olarak belirlenmiştir (Tablo 2).. Katılımcıların puan ortalamaları değerlendirildiğinde algılanan kontrol alt boyutu en yüksek değer ile beden eğitimi dersi için kaygının yüksek olduğu söylenebilir. Ayrıca fiziksel gerginlik alt boyutu ise en düşük puan aldığı görülüyor ve katıımcıların fiziksel gerginlik düzeylerinin ortalamanın altında olduğu söylenebilir. 
Tablo 2. Lise öğrencilerinin beden eğitimi ve spor dersi sınav kaygısı ölçeğinden aldıkları puanların ortalama, standart sapma ve minimum-maksimum değerleri.

\begin{tabular}{|c|c|c|c|c|c|}
\hline Boyutlar & $\mathbf{N}$ & $\bar{x}$ & SS & Min. & Max. \\
\hline Endişe & & 2.51 & .78 & 1.00 & 4.00 \\
\hline $\begin{array}{l}\text { Kendi Kendine } \\
\text { Odaklanma }\end{array}$ & & 1.92 & .91 & 1.00 & 4.00 \\
\hline Bedensel Belirtiler & & 1.73 & .68 & 1.00 & 4.00 \\
\hline Fiziksel Gerginlik & 454 & 1.45 & .65 & 1.00 & 4.00 \\
\hline Algılanan Kontrol & & 2.98 & .76 & 1.00 & 4.00 \\
\hline $\begin{array}{l}\text { Beden Eğitim Dersi } \\
\text { Sınav Kaygısı }\end{array}$ & & 2.13 & .40 & 1.32 & 3.79 \\
\hline
\end{tabular}

Araştırmaya katılan katıımcıların cinsiyetlerine göre beden eğitimi dersi sınav kaygısı puan ortalamalarını karşılaştırmak için bağımsız örneklemler t testi uygulanmıştır. Test sonucuna göre katıımcıların cinsiyetlerine göre beden eğitimi dersi sınav kaygısından almış oldukları puan ortalamaları arasında istatistiksel olarak anlamlı bir fark olduğu görülmektedir ( $p>0.05$ ). Araştırmaya katılan kız öğrencilerin erkek öğrencilere göre algıladıkları stres düzeyinin daha yüksek olduğu söylenebilir (Tablo 3).

Tablo 3. Katılımcıların cinsiyete göre beden eğitimi dersi sınav kaygısı puan ortalamalarının karşılaştırılması.

\begin{tabular}{lccccc}
\hline \multicolumn{1}{c}{ Cinsiyet } & $\mathbf{n}$ & $\bar{x}$ & SS & $\mathbf{t}$ & $\boldsymbol{p}$ \\
\hline Erkek & 162 & 2.07 & .38 & 2.59 & $\mathbf{0 . 0 1 0 ^ { * }}$ \\
$\mathrm{KIZ}$ & 292 & 2.17 & .40 & & \\
\hline${ }^{*} p<0.05$ & & & & &
\end{tabular}

Tablo 4 incelendiğinde ise araştırmaya katılan öğrencilerin spor yapma durumlarına göre istatistiksel olarak anlamlı bir fark olmadığı görülmektedir ( $p>0.05$ ).

Tablo 4. Katılımcıların spor yapma durumlarına göre beden eğitimi dersi sınav kaygısı puanlarının karşılaştırılması.

\begin{tabular}{cccccc}
\hline $\begin{array}{c}\text { Spor Yapma } \\
\text { Durumu }\end{array}$ & $\mathbf{n}$ & $\bar{x}$ & SS & $\mathbf{t}$ & $\mathbf{p}$ \\
\hline Spor Yapiyor & 206 & 2.14 & .38 & .155 & 0.087 \\
Spor Yapmiyor & 248 & 2.13 & .41 & & \\
\hline
\end{tabular}


Tablo 5. Beden eğitimi ve spor dersi sınav kaygısı ölçeği puanlarının sınıf düzeyine göre tek yönlü varyans analizi (one way ANOVA) sonuçları.

\begin{tabular}{lrrrrl}
\hline Sınıf Düzeyi & $\mathbf{n}$ & $\bar{x}$ & SS & $\mathbf{F}$ & $\boldsymbol{p}$ \\
\hline 9. Sinıf (1) & 108 & 2.11 & .4 & & \\
10. Sinıf (2) & 124 & 2.13 & .39 & & \\
11. Sinıf (3) & 113 & 2.14 & .39 & 0.094 & 0.096 \\
12. Sinıf (4) & 109 & 2.13 & .41 & & \\
\hline
\end{tabular}

Araştırmaya katılan katılımcıların sınıf düzeyine göre beden eğitimi ve spor dersi sınav kaygısı ölçeğinden almış oldukları puan ortalamalarını karşılaştırmak için tek yönlü varyans analizi uygulanmıştır. Analiz sonucuna göre katılımcıların sınıf düzeyine göre beden eğitimi ve spor dersi sınav kaygısı ölçeğinden almış oldukları puan ortalamaları arasında istatistiksel olarak anlamlı bir fark olmadığı tespit edilmiştir. $(p<0.05)$.

\section{Tartışma}

Bu araştırmada, lise öğrencilerinin beden eğitimi ve spor dersi sınav kaygılarının cinsiyet, spor yapma durumu ve sınıf düzeyi değişkenleri açısından incelenmesi amaçlanmıştır. Bu amaç doğrultusunda katıımcıların ölçek geneli ve alt boyutları cinsiyete, spor yapma durumlarına ve sınıf düzeylerine göre beden eğitimi ve spor dersi sınav kaygısı düzeyleri değerlendirilmiştir. Ayrıca beden eğitimi ve spor dersi sınav kaygısı ölçeği alt boyutlarına ait kaygı düzeyi bulguları araştırımıştır.

Araştırmanın bulgularında katıımcıların cinsiyetlerine göre beden eğitimi dersi sınav kaygısından almış oldukları puan ortalamaları arasında istatistiksel olarak anlamlı bir fark olduğu görülmüştür. Araştırmaya katılan kız öğrencilerin erkek öğrencilere göre algıladıkları stres düzeyinin daha yüksek olduğu söylenebilir. Literatür incelendiğinde bu sonuçla paralellik gösteren çalışmalara rastlanmıştır. Aba (2018) yaptığı araştırma neticesinde sınav kaygısının, akademik başarı üstündeki etkisinin erkeklerde daha yüksek olduğu görülmüştür. Lakot (2019) 8. sınıfta okuyan öğrencilerin, sınav kaygısı ile fiziksel aktivite düzeyleri ve beden eğitimi dersine ilişkin yatkınlıkları arasındaki ilişkileri incelemek amacıyla yapmış olduğu araştırmada cinsiyete göre anlamlı farklılık olduğu ve kadınların erkeklere göre daha yüksek puan aldığı belirtilmiştir. Diğer bir çalışmada ise Kilit (2019) üniversite öğrencilerinde belirsizliğe tahammülsüzlük, endişe ve bilişsel sınav kaygısı ilişkisini incelemiştir. Sınav kaygısı puanının cinsiyete göre farklılaştığı ve kadın katılımcıların sınav kaygı puanların erkeklere göre daha yüksek olduğu sonucu ortaya çıkmıştır. Bilir (2019) üniversite sınavına hazırlanan öğrencilerde ana-baba tutumu ile sınav kaygısı arasındaki ilişkiyi incelediği çalışmasında benzer sonuçlara ulaşmıştır. Sınav kaygısı puanının cinsiyete göre farklılaştığı ve kadın öğrencilerin istatiksel olarak daha anlamlı olduğu belirtilmektedir. Uluslararası literatürde de benzer sonuçlara ulaşan çalışmalar mevcuttur. Mohammadyari (2012) yaptığı araştırmada kadın öğrencilerin erkek öğrencilere göre daha fazla sınav kaygısı puanı aldığını belirtmişlerdir. Berger ve Shechter (1996) kız öğrencilerin zorluklar karşısında erkek öğrencilere göre daha savunmasız kaldıklarını dolayısıyla kaygı puanlarının yüksek olduğunu vurgulamışlardır. Literatür taraması sonucu ulaşılan çalışmalar bu araştırmayı destekler niteliktedir.

Araştırmanın bir diğer bulgusunda ise araştırmaya katılan öğrencilerin spor yapma durumlarına göre istatistiksel olarak anlamlı bir fark olmadığı görülmüştür. Literatürde bu çalışma ile tezat olan çalışmalar mevcuttur. Pöschl'ün (2017) 14-19 yaş aralığındaki adölesan kişilerde görülebilme intimali olan postural bozukluklarını, fiziksel aktivite düzeylerini ve sınav kaygılarını değerlendirmeyi amaçladığı çalışmasında 
bu çalışmayla benzerlik gösterecek şekilde sınav kaygısı ile fiziksel aktivite ve postural bozukluk arasında anlamlı bir ilişki bulunamamıştır. Bu bulguların aksine fiziksel aktivite yapma ile kaygı arasında anlamlı ilişkinin olduğu sonucuna ulaşan çalışmalar da mevcuttur. Dalkıran (2012) tarafından yapılmış dershanede okuyan öğrencilerin fiziksel aktiviteye katıımına ilişkin sürekli kaygı, sınav kaygısı ve sosyal beceri seviyeleriyle sınav başarılarının incelendiği çalışmada fiziksel aktivite yapanların, kaygı seviyelerinin anlamlı şekilde düşük olduğu, sosyal beceri düzeylerinin se anlamlı şekilde yüksek olduğu görülmüştür.

Araştırmaya katılan katıımcıların sınıf düzeyine göre beden eğitimi ve spor dersi sınav kaygısı ölçeğinden almış oldukları puan ortalamalarını değerlendirildiğinde beden eğitimi ve spor dersi sınav kaygısı ölçeğinden almış oldukları puan ortalamaları arasında istatistiksel olarak anlamlı bir fark olmadığı sonucu ortaya çıkmıştır. Literatür incelendiğinde sınıf düzeyi ile paralel bir değişken olan yaş ile kaygı arasında da anlamlı farklılaşmaların olmadığı çalışmalara rastlanmıştır. Ün'ün (2018) üniversite sınavına hazırlanan öğrencilerde sınav kaygısı, mükemmeliyetçilik ve anne baba tutumu arasındaki ilişkiyi incelemek amacıyla yapmış olduğu çalışmada sınav kaygısı ile yaş değişkeni arasında anlamlı farklılık olmadığı belirtilmiştir. Benzer şekilde Kilit (2019) üniversite öğrencilerinde belirsizliğe tahammülsüzlük, endişe ve bilişsel sınav kaygısı ilişkisini araştırdığı çalışmasında sınav kaygısı puanının yaşa göre farklılaşmadığı sonucu ortaya çıkmıştır. Üniversite sınavına hazırlanan öğrencilerle başka bir çalışmada da yaş ile sınav kaygısı arasında anlamlı bir ilişki bulunamamıştır (Bilir, 2019). Ulaşılan bulgular bu araştırmayı destekler niteliktedir ancak araştırma ile tezatıı gösteren çalışmalarda mevcuttur. Genç (2013) ortaokulda okuyan öğrencilerin, sınıf ve cinsiyet değişkenine göre sınav kaygı seviyesinin belirlenmesini amacıyla bir araştırma yapmış ve sınav kaygı puanlarında sınıflar arasında anlamlı fark bulunduğunu ortaya çıkmıştır. Öğrencilerin üst sınıflara çıktıkça sınav kaygısını daha fazla yaşadığı sonucuna ulaşmıştır.

Araştırmanın bulgularında lise öğrencilerinin beden eğitimi ve spor dersi sınav kaygısı ölçeği alt boyutları endişe alt boyutu, kendi kendine odaklanma alt boyutu, bedensel belirtiler alt boyutu, fiziksel gerginlik alt boyutu ve algılanan kontrol alt boyutu düzeyleri değerlendirilmiştir. Katılımcıların puan ortalamaları değerlendirildiğinde algılanan kontrol alt boyutu en yüksek değer ile beden eğitimi dersi için kaygının yüksek olduğu sonucuna ortaya çıkmıştır. Ayrıca fiziksel gerginlik alt boyutu ise en düşük puan aldığı görülmüştür ve katıımcıların fiziksel gerginlik düzeylerinin ortalamanın altında olduğu sonucuna ulaşılmışırı.

Sonuç olarak; lise öğrencilerinin beden eğitimi ve spor dersi sınav kaygısı düzeyleri sınıf düzeyine ve spor yapma durumuna göre farklılaşmadığı ancak cinsiyete göre farklılaştığı ortaya çıkmıştır. Kız öğrencilerin erkek öğrencilere nazaran beden eğitimi ve spor dersi sınav kaygısı düzeyleri daha yüksektir. Ayrıca lise öğrencilerinin algılanan kontrol düzeylerinin yüksek, fiziksel gerginlik düzeylerinin ise düşük olduğu sonucuna ulaşılmıştır.

\section{Sonuç}

$\mathrm{Bu}$ araştırma kesitsel veri toplanarak yapılmış bir çalışmadır. Bu nedenle, çalışmadaki bağımsız değişkenlerin lise öğrencilerinin beden eğitimi ve spor dersi kaygı düzeylerine etkisini ortaya koyacak daha uzun dönemli ve boylamsal çalışmalar yapılabilir. Ayrıca konunun daha derinlemesine incelenebilmesi için farklı örneklemlerde ve farklı modellerde kurgulanmış çalışmaların yapılması önerilmektedir. Sınav kaygısının nedenlerini ortaya çıkaracak nitel çalışmaların yapılması literatüre katkı sağlayabileceği gibi okul türü (özel okul ve devlet okulu), akademik başarı, ailenin gelir durumu gibi farklı değişkenlerin sınav kaygısı üzerindeki etkisi de test edilebilir. Yapılan incelemede, öğretmenlerin ve ebeveynlerin lise öğrencilerinin beden eğitimi ve spor dersi sınav kaygısı düzeylerine ilişkin görüşlerinin 
ele alındığı çalışmalar noktasında literatürde bir boşluk bulunduğu görülmüştür. Bu nedenle bu konunun ele alındığı çalışmaların yapılması literatüre katkı sağlayabilir.

\section{Kaynakça}

Atchley, R. C. (1970). Recreation and Leisure. In understanding American Society: The dynamics of social institutions. Belmont, Calif: Wadsworth.

Aba, D. (2018). Öğrencilerin sınav kaygısı ile akademik başarı arasındaki cinsiyet farklıı̆̆ı. (Yayımlanmamış yüksek lisans tezi). Üsküdar Üniversitesi Sosyal Bilimler Enstitüsü, İstanbul.

Bay, E., Tuğluk, N.M., Gençdoğan, B. (2004), Üniversite öğrencilerinin kaygı düzeyleri ile ders çalışma tutum ve alışkanlıklarının incelenmesi. Psikoloji Dergisi, 7(25), 33-39.

Beidel, D. C. (1991). Social phobia and overanxious disorder in school-age children. Journal of the American Academy of Child and Adolescent Psychiatry, 30(4), 545-552. 10.1097/00004583-199107000-00003

Berger, R. \& Shechter, Y. (1996). Guidelines for choosing an intervention package for working with adolescent girls in distress. Adolescence, 31, 709-719.

Büyüköztürk, Ş., Kılıç-Çakmak, E., Akgün, Ö.E., Karadeniz, Ş. ve Demirel, F. (2014). Bilimsel araştırma yöntemleri. Ankara: Pegem.

Chapell, M. S., Blanding, Z. B., Silverstein, M. E., Takahashi, M., Newman, B., Gubi, A. \& McCann, N. (2005). Test anxiety and academic performance in undergraduate and graduate students. Journal of Educational Psychology, 97(2), 268-274. https://doi.org/10.1037/0022-0663.97.2.268

Cüceloğlu, D.(2015). insan ve Davranışı Psikolojinin Temel Kavramları. İstanbul: Remzi.

Dalkıran, O. (2012). Dershane öğrencilerinin fiziksel aktivitede bulunma değişkenine göre sürekli kaygı, sınav kaygısı ve sosyal beceri düzeyleri ile sınav performanslarının değerlendirilmesi. (Yayımlanmamış doktora tezi). Ankara Üniversitesi Sağlık Bilimleri Enstitüsü, Ankara.

Danthony, S., Mascret, N., \& Cury, F. (2020). Test anxiety in physical education: The predictive role of gender, age, and implicit theories of athletic ability. European Physical Education Review, 26(1), 128-143. https://doi.org/10.1177/1356336X19839408

Devrilmez, E., Çiy, D., Bilgiç, M. ve Dervent, F. (2021). Beden Eğitimi ve Spor Dersi Sınav Kaygısı Ölçeğinin Türkçe geçerlik ve güvenirliği. Beden Eğitimi ve Spor Araştırmaları Dergisi, 13(1), 1-13.

Genç, M. (2013). ilköğretim öğrencilerinin sınıf ve cinsiyete göre sınav kaygı düzeylerinin belirlenmesi. CBÜ Sosyal Bilimler Dergisi, 11(1), 85-95.

Gökçe, H. (2015). Rekreasyonel etkinliklerin üniversiteye giriş sınavına hazırlanan bireylerin öz-yeterlik, sınav kaygısı ve serbest zaman doyum düzeyleri üzerine etkisi. Doktora tezi. Ankara Üniversitesi Sağlık Bilimleri Enstitüsü, Ankara.

Karasar, N. (2017). Bilimsel araştırma yöntemi. Ankara: Nobel.

Kayapınar, E. (2006). Ortaöğretim kurumları öğrenci seçme ve yerleştirme sınavı (OKS)'na hazırlanan ilköğretim 8. sınıf öğrencilerinin kaygı düzeylerinin incelenmesi. (Yayımlanmamış yükseklisans tezi). Kocatepe Üniversitesi, Sosyal Bilimler Enstitüsü, Afyonkarahisar. 
Kilit, Z. (2019). Üniversite Öğrencilerinde Belirsizliğe Tahammülsüzlük, Endişe ve Bilişsel Sınav Kaygısı Ilişsisi. (Yayımlanmamış yüksek lisans tezi). Üsküdar Üniversitesi Sosyal Bilimler Enstitüsü, İstanbul.

Lakot, H. (2019). 8. Sını Öğrencilerinin Sınav Kaygısı ile Fiziksel Aktivite Düzeyleri ve Beden Eğitimine Ilişkin Yatkınlıklarının incelenmesi. (Yayımlanmamış yüksek lisans tezi). Trabzon Üniversitesi, Lisansüstü Eğitim Enstitüsü, Trabzon.

Öner, N., \& Le Compte, A. (1998). Sürekli Durumluk/Sürekli Kaygı Envanteri El Kitabı. İstanbul: Boğaziçi Üniversitesi.

Pöschl, G. (2017). 14-19 yaş aralığındaki adölesan bireylerde postüral değişikliklerin fiziksel aktivite ve sınav kaygısının değerlendirilmesi. Bahçeşehir Üniversitesi Sağlık Bilimleri Enstitüsü, İstanbul.

Putwain, D. W. (2007). Test anxiety in UK schoolchildren: Prevalence and demographic patterns. British Journal of Educational Psychology, 77(3), 579-593.

Putwain, D. W., Woods, K., \& Symes. W. (2010) Personal and situational predictors of test anxiety of students in post-compulsory education. British Journal of Educational Psychology, 80, 137-160. https://doi.org/10.1348/000709909X466082

Tekbaş, S. (2009). Edirne merkez ilçede ilköğretim son sınıf öğrencilerinde OKS ve lise son sınıf öğrencilerinde ÖSS üzerinden sınav kaygısı ve etkileyen etmenler. (Yayımlanmamış yüksek lisans tezi). Trakya Üniversitesi, Sağlık Bilimleri Enstitüsü, Edirne.

Travlos, A. K. (2010). High intensity physical education classes and cognitive performance in eighth-grade students: An applied study. International Journal of Sport and Exercise Psychology, 8(3), 302-11.

Ün, M. D. (2018). Üniversite Sınavına Hazırlanan Öğrencilerde Sınav Kaygısı, Mükemmeliyetçilik ve Anne Baba Tutumu Arasındaki iliş̧kinin incelenmesi. (Yayımlanmamış yüksek lisans tezi). Üsküdar Üniversitesi, Sosyal Bilimler Enstitüsü, İstanbul.

Yusefzadeh, H., Iranagh, J. A., \& Nabilou, B. (2019). The effect of study preparation on test anxiety and performance: a quasi-experimental study. Advances in Medical Education and Practice, 10, 245.

Zeidner, M. (1998). Test Anxiety: The State of the Art. New York: Plenum. 